\title{
NOTES
}

\section{Preparation of Linear Low Density Polyethylene with Titanium Tetra-n-butoxide-Diethylaluminum Chloride Catalyst in Slurry Phase}

\author{
Dong-ho LEE, ${ }^{\dagger}$ Kyung-eun MIN, and Tae-oan AHN* \\ Department of Polymer Science, College of Engineering, \\ Kyungpook National University, Taegu, Korea \\ * Department of Chemical Technology, College of Engineering, \\ Seoul National University, Seoul, Korea
}

(Received August 4, 1986)

\begin{abstract}
KEY WORDS Low Density Polyethylene / Titanium Tetra- $n$-butoxide / Diethylaluminum Chloride / Slurry Phase / Copolymerization / Catalytic Activity / 1-Butene Content /
\end{abstract}

In addition to low density polyethylene (LDPE) and high density polyethylene (HDPE), the copolymers of ethylene and $\alpha$ olefin (1-butene, 1-hexene or 1-octene) were recently prepared and named linear low density polyethylene (LLDPE). ${ }^{1} \quad$ Because LLDPE has better physical properties of melting point, rigidity, low impact temperature, tensile strength and elongation compared to LDPE, commercial interest has naturally gravitated. Recently Soga et al. used the supported titanium butoxide catalyst for the production of ethylene-propylene rubber. ${ }^{2}$

We would like to report the preparation of LLDPE by copolymerization of ethylene and 1-butene in the slurry phase using titanium tetra- $n$-butoxide-diethylaluminum chloride catalyst and the effects of aging time and concentration of catalyst components on catalytic activity and 1-butene content of copolymer produced.

The monomers of ethylene and 1-butene supplied by the Dae-han Petrochemical Co., Korea were used without any purification. The catalyst components of diethylaluminum chloride (DEAC) obtained from the Daehan Petrochemical Co., Korea, and titanium tetra- $n$-butoxide (TTB) of Alfa Chemical Co., U.S.A. were diluted with distilled $n$-hexane.

The high-pressure reactor (Parr Instrument Co., U.S.A.) equipped with temperature regulator and circulating water bath (Julabo F40, West Germany) was used as a reaction vessel. After $150 \mathrm{ml}$ of $n$-hexane and appropriate amounts of catalyst components were added, the polymerization reaction was carried out by charging the comonomer mixture $\left(94.2 \pm 0.7 \mathrm{~mol}^{\circ} \%\right.$ of ethylene and $5.8 \pm 0.7$ $\mathrm{mol} \%$ of 1-butene) with $4 \mathrm{~kg} \mathrm{~cm}^{-2}$ of total pressure. In order to evaluate catalytic activity, the weight of copolymer produced per gram of titanium tetra- $n$-butoxide was calculated and expressed by g-polymer/g-Ti.

The 1-butene content in copolymer was determined using IR spectrophotometer (Perkin-Elmer 282 B, U.S.A.) by Bryant meth$\mathrm{od}^{3}$ and ${ }^{13} \mathrm{C}$ NMR of Queen's University, Canada. $^{4}$

The aging time, the contact period of both catalyst components affects the catalytic ac-

\footnotetext{
* To whom correspondence should be addressed.
} 
tivity markedly. It has been reported that the polymerization rate decreased gradually with the increase of catalyst aging time for the preparation of poly(ethylene-propylene) with $\mathrm{Al}\left(\mathrm{C}_{5} \mathrm{H}_{13}\right)_{3}-\mathrm{VCl}_{4}{ }^{5}$ and poly(ethylene-1butene) by $\mathrm{Cp}_{2} \mathrm{TiCl}_{2}$-(iso- $\left.\mathrm{Bu}\right) \mathrm{AlCl}_{2}{ }^{6}$. For this TTB-DEAC catalyst system, the effects of aging time on the catalytic activity and 1butene content of the copolymer were investigated and plotted in Figure 1. As seen at this figure, the catalytic activity was almost independent of aging time up to 60 minutes but decreased for longer aging time. This tendency was believed to be due to the decrease of active sites on the catalyst in the absence of monomer. ${ }^{7}$ The 1-butene content of the copolymer also decreased for longer aging time which could be explained by the overreduction of $\mathrm{Ti}^{3+}$ species to $\mathrm{Ti}^{2+}$ species. The correlation has been well established between the oxidation states of titanium and polymerization activities of various olefins, i.e., the $\mathrm{Ti}^{3+}$ species are active for all olefins whereas the $\mathrm{Ti}^{2+}$ species only for ethylene. ${ }^{8,9}$ Therefore the aging time of 60 minutes was good for the catalytic activity and 1-butene content of the copolymer.

For the propylene polymerization using $\mathrm{VCl}_{4}$-DEAC catalyst at constant concentration of $\mathrm{VCl}_{4}$, the polymer yield increased but the weight-average molecular weight decreased with increasing the DEAC concentration..$^{10}$ According to the study of Natta $e t$ $a l$. on the copolymerization of ethylene and propylene by $\mathrm{VCl}_{4}$-trihexylaluminum (THA) catalyst with constant concentration of $\mathrm{VCl}_{4}$, the conversion had a maximum at the $[\mathrm{THA}] /\left[\mathrm{VCl}_{4}\right]$ ratio of $2.5 .^{5}$

Therefore the catalytic activity and 1-butene content of the copolymer were examined for different concentrations of DEAC at constant concentration of TTB and are given at Figure 2. As shown in Figure 2, the copolymer was not produced below the [DEAC]/[TTB] ratio of 8 and for higher ratio the catalytic activity increased with the concentration of DEAC.

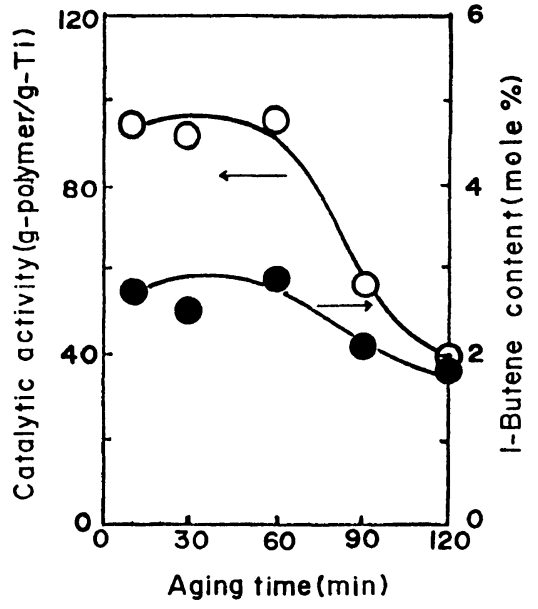

Figure 1. Effects of aging time on the catalytic activity and 1-butene content of the copolymer for the copolymerization of ethylene and 1-butene with TTBDEAC catalyst: $\left[\mathrm{C}_{2} \mathrm{H}_{4}\right] /\left[\mathrm{C}_{4} \mathrm{H}_{8}\right]=94.2 / 5.8 ; \quad[\mathrm{TTB}]=$ $3.52 \times 10^{-4} \mathrm{~mol} \mathrm{l}^{-1} ;[\mathrm{DEAC}] /[\mathrm{TTB}]=15.7$; diluent, 150 $\mathrm{ml} n$-hexane; temperature, $70^{\circ} \mathrm{C}$; pressure, $4 \mathrm{~kg} \mathrm{~cm}^{-2}$; polymerization time, $1 \mathrm{~h}$.

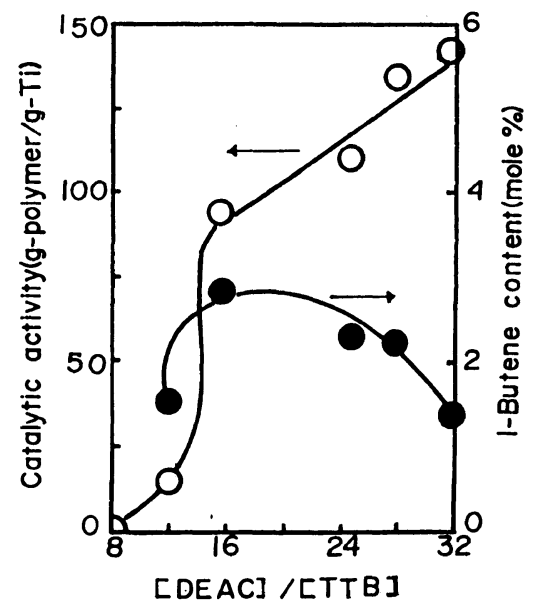

Figure 2. Effects of $[\mathrm{DEAC}] /[\mathrm{TTB}]$ ratio on the catalytic activity and 1-butene content of the copolymer for the copolymerization of ethylene and 1-butene with TTB-DEAC catalyst: $\left[\mathrm{C}_{2} \mathrm{H}_{4}\right] /\left[\mathrm{C}_{4} \mathrm{H}_{8}\right]=94.2 / 5.8$; $[\mathrm{TTB}]=$ $3.52 \times 10^{-4} \mathrm{~mol} \mathrm{l}^{-1}$; diluent, $150 \mathrm{ml} n$-hexane; temperature, $70^{\circ} \mathrm{C}$; aging time, $60 \mathrm{~min}$; pressure, $4 \mathrm{~kg} \mathrm{~cm}^{-2}$; polymerization time, $1 \mathrm{~h}$.

But the 1-butene content of the copolymer had a maximum near [DEAC]/[TTB] ratio of 16 and decreased above this maximum due to the 


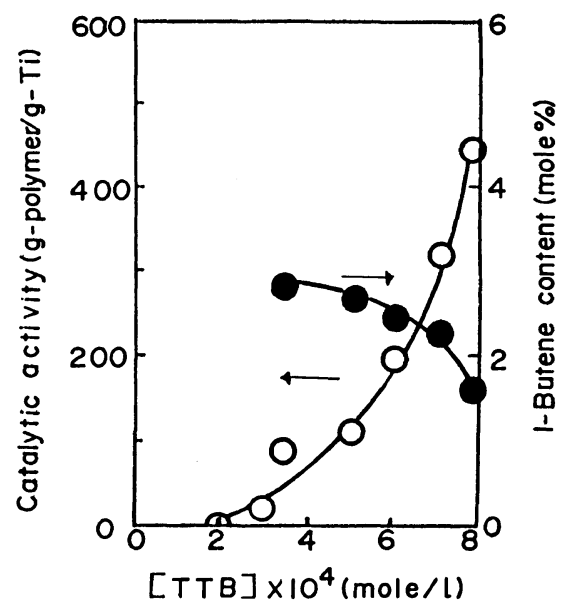

Figure 3. Effects of [TTB] on the catalytic activity and 1-butene content of the copolymer for the copolymerization of ethylene and 1-butene with TTB-DEAC catalyst: $\left[\mathrm{C}_{2} \mathrm{H}_{4}\right] /\left[\mathrm{C}_{4} \mathrm{H}_{8}\right]=94.2 / 5.8 ; \quad[\mathrm{DEAC}] /[\mathrm{TTB}]=$ 15.7; diluent, $150 \mathrm{ml} n$-hexane; temperature, $70^{\circ} \mathrm{C}$; aging time, $60 \mathrm{~min}$; pressure, $4 \mathrm{~kg} \mathrm{~cm}^{-2}$; polymerization time, $1 \mathrm{~h}$.

over-reduction of $\mathrm{Ti}^{3+}$ species for higher DEAC concentration.

In addition, the effects of TTB concentration at constant [DEAC]/[TTB] on catalytic activity and 1-butene content were measured and are shown at Figure 3. As shown in Figure 3 , the minimum TTB concentration of $2 \times$ $10^{-4} \mathrm{moll}^{-1}$ was necessary for the production of the copolymer and above this value the catalytic activity increased with TTB concen- tration. Catalytic activity increase may be due to the increase of active site number and the change of the nature of the active site (increase of $k_{\mathrm{p}}$ ) because the amounts of incorporated 1-butene units in copolymers decreased with increase of TTB concentration at constant $\left[\mathrm{C}_{2} \mathrm{H}_{4}\right] /\left[\mathrm{C}_{4} \mathrm{H}_{8}\right]$.

Acknowledgement. This work was supported by the Korea Research Foundation at 1983.

\section{REFERENCES}

1. F. W. Billmeyer, Jr., "Textbook of Polymer Science," 3rd ed, John-Wiley \& Sons, New York, N.Y., 1984, p 370.

2. T. Keii and K. Soga, Ed., "Catalytic Polymerization of Olefins," Kodansha, Tokyo, 1986, p 109.

3. W. M. D. Bryant and R. C. Votor, J. Am. Chem. Soc., 75, 6113 (1959).

4. B. K. Hunter, K. E. Russell, M. V. Scammel, and S. L. Thompson, J. Polym. Sci., Polym. Chem. Ed., 22, 1383 (1984).

5. G. Natta, G. Mazzanti, A. Valvassori, and G. Sartori, J. Polym. Sci., 51, 429 (1961).

6. I. D. Rubin, J. Polym. Sci. A-1, 5, 1119 (1967).

7. D. H. Lee and C. C. Hsu, J. Appl. Polym. Sci., 25, 2373 (1980).

8. K. Soga, S. I. Chen, and R. Ohnishi, Polym. Bull., 10, 168 (1983).

9. K. Soga, M. Ohtake, R. Ohnishi, and Y. Doi, Polym. Commun., 25, 171 (1984).

10. A. Zambelli, G. Natta, I. Pasquon, and R. Signorini, J. Polym. Sci., C, 16, 2485 (1967). 